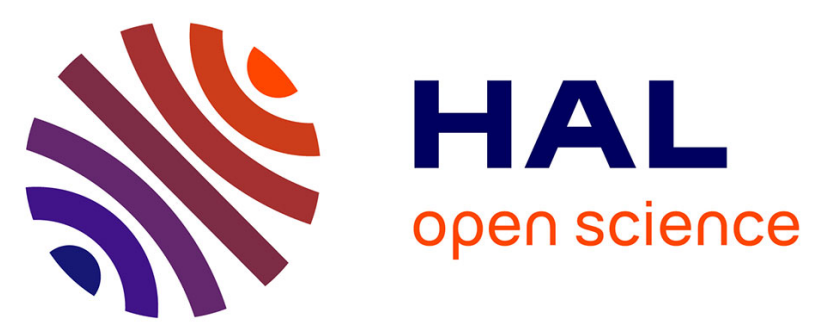

\title{
Scale-down emulsion homogenization: Conditions to mimic pilot homogenizer depending on the emulsifier
}

Baptiste M.G. Michon, Pablo Granda, Damien J.L. Mat, Isabelle Souchon, Steven Le Feunteun, Camille Michon

\section{- To cite this version:}

Baptiste M.G. Michon, Pablo Granda, Damien J.L. Mat, Isabelle Souchon, Steven Le Feunteun, et al. Scale-down emulsion homogenization: Conditions to mimic pilot homogenizer depending on the emulsifier. Journal of Food Engineering, 2019, 261, pp.117-124. 10.1016/j.jfoodeng.2019.06.003 . hal-02265920

\author{
HAL Id: hal-02265920 \\ https://hal.science/hal-02265920
}

Submitted on 12 Aug 2019

HAL is a multi-disciplinary open access archive for the deposit and dissemination of scientific research documents, whether they are published or not. The documents may come from teaching and research institutions in France or abroad, or from public or private research centers.
L'archive ouverte pluridisciplinaire HAL, est destinée au dépôt et à la diffusion de documents scientifiques de niveau recherche, publiés ou non, émanant des établissements d'enseignement et de recherche français ou étrangers, des laboratoires publics ou privés. 


\title{
Scale-down emulsion homogenization: Conditions to mimic pilot homogenizer depending on the emulsifier
}

\author{
Baptiste M.G. Michon ${ }^{\mathrm{a}}$, Pablo Granda ${ }^{\mathrm{a}}$, Damien J.L. Mat ${ }^{\mathrm{a}, \mathrm{b}}$, Isabelle Souchon ${ }^{\mathrm{b}}$, \\ Steven Le Feunteun ${ }^{\mathrm{b}}$, Camille Michon ${ }^{\mathrm{a}, *}$ \\ a Ingénierie Procédés Aliments, AgroParisTech, INRA, Université Paris-Saclay, 91300, Massy, France \\ ${ }^{\mathrm{b}}$ UMR GMPA, AgroParisTech, INRA, Université Paris-Saclay, 78850, Thiverval-Grignon, France
}

A R T I C L E I N F O

\section{Keywords:}

Chemical-physics

Process

Lecithin

Whey protein

Emulsion

Structure

\begin{abstract}
A B S T R A C T
The standard tool for emulsification during formulation trials is a homogenizer, which unfortunately requires too much raw material and is time consuming. A lab-scale process using a rotor-stator shearing step followed by ultrasound treatment was designed, both with lecithin and whey protein, for emulsification as efficient as in pilot-plant trials. Ranges for the lab-scale process were defined (rotor-stator: $5 \mathrm{~min}, 5000-10000 \mathrm{rpm}$; sonication time: $2-10 \mathrm{~min}$ ). Process conditions were identified to obtain both emulsions with the same structure at lab and pilot scales: for lecithin, respectively shearing at $10000 \mathrm{rpm} / 10 \mathrm{~min}$ sonication and high pressure for both pilot stages. However, due to protein denaturation, some conditions differed for whey proteins: shearing at $5000 \mathrm{rpm}$ instead of $10000 \mathrm{rpm}$ (all the other parameters being unchanged). Finally, recommendations concerning the position of the ultrasound probe and temperature control are provided to insure good reproducibility.
\end{abstract}

\section{Introduction}

The vast majority of food products contain an aqueous phase and an oil phase, which are immiscible. The aqueous phase can be dispersed in the oil continuous phase in the form of droplets, leading to water-in-oil emulsions (w/o), such as butter. The opposite is also possible: dispersing the oil phase in the form of oil droplets in a continuous aqueous phase, leading to oil-in-water $(\mathrm{o} / \mathrm{w})$ emulsions. These are the two most common forms in sauces, yogurts and cream desserts. Both types of emulsion can be obtained by adapting different parameters: the proportion of the oil and aqueous phases, the order in which components are added, and the manufacturing process (Canselier and Poux, 2004a, 2004b; McClements, 2015). This process usually includes one or more stages of relatively intense mixing, which makes it possible to form droplets and reduce their size (Walstra, 1983, 1993).

Emulsions are stabilized using surfactant molecules made out of at least one hydrophobic and one hydrophilic moiety (Dickinson, 1992). As they have an affinity for both oil and water phases, they can localize at the interface between the droplets, stabilizing it by reducing the surface tension, and making it more resilient. In all emulsion systems, droplets will either tend to stay away from one another, or stick together, creating aggregates. Their behavior mainly depends on the surfactant steric repulsion, on its ionic charge, and on the type of emulsion (w/o or o/w). When aggregation occurs, if the droplet interfaces are not sufficiently stable, in the end, they will break up. Droplets merge (coalescence phenomenon), their average diameter increases, modifying the system properties, especially its stability. Since the aqueous and oil phases have different densities, emulsions are unstable by nature. Droplets in o/w emulsions tend to rise (creaming phenomenon), while droplets in w/o systems tend to drop (sedimentation phenomenon). In both cases, the movement of droplets is driven by gravity, making the size of droplets a major factor in stability. Referring to Stoke's law, several parameters can be adjusted to slow destabilization: apart from reducing the size of droplets, the viscosity of the continuous phase can be increased, the surface tension can be reduced, or the densities of the two fluids can be balanced (Walstra, 1993).

The composition of emulsions can influence each of these parameters, thus playing a very important role. Many different surfactants are used in the food industry. Most can be found naturally in various ingredients, making it possible to exploit their emulsification properties in situ. At the industrial level, they can be extracted and purified (Dickinson, 1992), ready to be incorporated at the appropriate moment during the process, to optimize the properties of the end product. There are three main categories of surfactant species: molecules, macromolecules and submicron particles. Surface-active molecules, such as lecithin or fatty acids, are small in size and move rapidly towards

\footnotetext{
* Corresponding author.

URL: http://camille.michon@agroparistech.fr (C. Michon).
} 
interfaces through diffusive mechanisms. They reduce the surface tension without giving elasticity to the interface. They are usually characterized by their hydrophilic/lipophilic balance (HLB), their molecular weight and their charge. These three characteristics determine the steric repulsion close to the interfaces and the strength of potential repulsion between droplets (Dickinson, 1992). Surface-active macromolecules, such as proteins, but also some cellulose derivatives, have much larger molecular masses, i.e. of several orders of magnitude. They generally have a succession of hydrophilic and hydrophobic zones, which allow them to adsorb at the interface and form loops and tails on both sides, providing a certain degree of elasticity (Dickinson, 1992). The ability to reorganize at the interface over long periods and the charge (amount, but also distribution of positive and negative charges across the molecule) of these macromolecules influence their surfactant potential and the level of repulsion/attraction between droplets (Mezdour et al., 2008). Finally, it has been shown that small particles are likely to localize at the oil/water interface and to stabilize it to a greater or lesser extent, mainly depending on the shape of the particles and their affinity for the two phases (Dickinson, 2015). For food products, microcrystalline celluloses (MCC), some small starches or whey protein aggregates have already been successfully used to stabilize emulsions (Gonzalez-Jordan et al., 2018; Nilson and Bergenstal, 2006). Still, most food products contain more than just one surfactant. As a result, surfactants almost always compete to occupy the interface both during the process and while the product is ageing. This can lead to a complete modification of the composition, and hence of the interfacial properties (Courthaudon and Dickinson, 1991; Dickinson and Iveson, 1993; Fang and Dalgleish, 1996).

When formulating new products or adapting old ones, for example, to try and reduce the oil content, it can be both difficult and costly to change factors at a large scale. For about 30 years, the most widely used device to make emulsions at a pilot scale has been the small highpressure homogenizer. One important advantage over the industrial scale is that it can be operated with only 1-2 L of sample, while accurately reproducing its shearing conditions. It is thus a more flexible and cheaper way to create emulsions in conditions that are nevertheless similar to those in industrial processes. Yet, even with this small homogenizer, only a few formulations can be tested per day using around $10 \mathrm{~L}$ of product each. Moreover, a decent amount of time is required to clean the device. Since only a few $\mathrm{mL}$ of products are needed to characterize emulsions during the earlier development stages, a lot of resources and time are wasted. To our knowledge, there have only been a few unpublished attempts to develop pilot plants designed to produce a few milliliters, like the one described by Burgaud et al. (1990), and the plants that do exist are not easily accessible to people who want to conduct formulation trials. In addition, not all research team have access to small high-pressure homogenizers, which are quite expensive. Developing protocols using lab-scale devices that would enable the rapid creation of small volumes of emulsions would thus be advantageous, provided the proper realistic conditions are found to match the oil droplet sizes and interfacial composition. Going even further, it would be ideal to establish connections between parameters from lab-scale devices and high-pressure homogenizers in order to minimize discrepancies between small and large-scale processes, and to guarantee the process can be scaled up to industrial production.

The aim of the present study was to design a lab-scale process to produce small volumes of emulsions with the same properties as emulsions obtained with a pilot-plant high-pressure homogenizer and to propose down scale process conditions depending on the type of emulsifier concerned. Emulsions stabilized using lecithin were produced both at lab scale and with the pilot-plant homogenizer using the largest possible process parameters for both scales, and the droplet size distributions were compared. These results were compared to those obtained using native whey proteins instead of lecithin. Recommendations are given for both surface-active species, for correspondence between lab-scale and pilot-plant parameters and for proper use of the lab-scale system.

\section{Materials and methods}

\subsection{Materials}

Purified water was obtained using a Milli-Q purification system (Millipore, Merck, Germany) and its conductivity was $6.6 .10^{-5} \mathrm{~S} \mathrm{~m}^{-1}$, as provided by the purification system. Whey protein isolate powder (Prolacta 95, $95 \mathrm{wt} \%$ of protein on dry basis) was obtained from Lactalis, France. The whey protein content was $72.9 \mathrm{wt} \%$, measured on dry powder by the Kjeldahl method (Nx6.25) after precipitation at pH4.6 in triplicate. It was probably slightly overestimated, as it was a total protein determination, and Prolacta may contain a small amount of caseins. However, the Prolacta powder was obtained by ultrafiltration, thus minimizing the amount of residual caseins. Moreover, casein micelles aren't thermal sensitive. In consequence, it can be considered that only the whey protein will behave differently at the droplets interface at the two investigated scales. It contained $5 \mathrm{wt} \%$ of water $\left(105^{\circ} \mathrm{C}\right.$, one night). Rapeseed oil (Fleur de colza, Lesieur, France), which is often used in oil-in-water emulsion preparations, was purchased at a local supermarket. Hydrolyzed lecithin solution (Emulfluid NGM, process $n^{\circ} 100882,58 \mathrm{wt} \%$ of lecithin), an ingredient commonly used in lecithin-based formulation, was obtained from Cargill (France).

\subsection{Processing of emulsions}

\subsubsection{Emulsion preparation at lab scale $(50-150 \mathrm{~mL})$}

Lecithin stabilized emulsion: amounts of hydrolyzed lecithin solution ranging from $0.5 \mathrm{~g}$ to $3.5 \mathrm{~g}$ were added in $10.0 \mathrm{~g}$ of rapeseed oil. A few minutes of stirring were enough to homogenize the solution. Water was then added in a $500 \mathrm{~mL}$ beaker ( $80 \mathrm{~mm}$ diameter, $150 \mathrm{~mm}$ height) to reach a final weight of $100 \mathrm{~g}$. A first emulsification was made using a rotor-stator homogenizer (Polytron PT3100D, Switzerland) fitted with a PTDA32/2-B250 probe for $5 \mathrm{~min}$, with rotation speed varying between 5000 and $10000 \mathrm{rpm}$. The emulsion was then treated with ultra-sound for between 2 and $10 \mathrm{~min}$ (effective time, with cycles of $10 \mathrm{~s}$ on/10 s off) to further reduce the size of the oil droplets (Bioblock Ultrasonic Processor $20 \mathrm{kHz}, 130 \mathrm{~W}$, fitted with a $13 \mathrm{~mm}$ diameter probe, adapted for $50-150 \mathrm{~mL}$ volume treatment). During the two-stage emulsification processes, the temperature within the sample was maintained at $18 \pm 2{ }^{\circ} \mathrm{C}$ using an ice bath, as followed with a probe. The entire process was carried out in the same beaker. A set of preliminary experiments allowed determining an optimal concentration for lecithin of $0.7 \mathrm{wt} \%$, corresponding to $1.2 \mathrm{~g}$ of hydrolyzed lecithin solution, as described in Section 3.2. Then, all lecithin stabilized emulsions were prepared by using this optimal amount.

Whey protein stabilized emulsion: $18.5 \mathrm{~g}$ of whey proteins were dispersed in $60 \mathrm{~g}$ of water and allowed to rehydrate under stirring at room temperature for at least $1 \mathrm{~h}$. Rapeseed oil $(10.0 \mathrm{~g})$ was then added with additional water to reach a final weight of $100 \mathrm{~g}$. The emulsification processes were similar to those described in the 'lecithin-stabilized emulsion' section: a first emulsion was made using a Polytron, before applying a sonication treatment to reduce the size of oil droplets. Final concentrations were respectively $16.7 \mathrm{wt} \%$ for whey proteins, and $10 \mathrm{wt} \%$ for rapeseed oil. They were chosen according to previously published studies (Mat et al., 2016, 2018; Oberli et al., 2018), as the present work was carried out within the same research project.

\subsubsection{Emulsion homogenization at pilot scale $(>1 \mathrm{~L})$}

Lecithin stabilized emulsion: $121 \mathrm{~g}$ of hydrolyzed lecithin solution were added in $1.0 \mathrm{~kg}$ of rapeseed oil. This solution was mixed with $8.88 \mathrm{~kg}$ of water using into the Process-Pilot 2000 dispersing system (15 $\mathrm{min}$ at $5610 \mathrm{rpm}$ ) to make a first emulsion. This emulsion was treated in a two-stage high-pressure homogenizer (GEA Niro SOAVI, type NS, 2002H, Italy) at variable pressures, to reduce and homogenize 


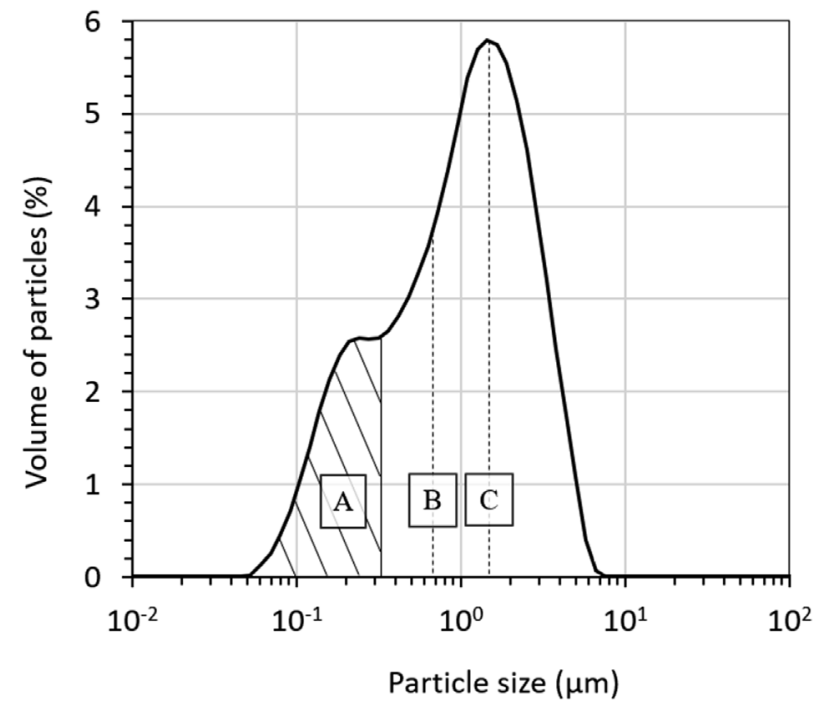

Fig. 1. Size distribution of oil droplets in a lab-made lecithin-stabilized emulsion (Lecithin concentration: $0.7 \mathrm{wt} \%$. Polytron: $7500 \mathrm{rpm}$ for $5 \mathrm{~min}$ followed by $6 \mathrm{~min}$ of sonication). The three parameters of interest are indicated as A: $\%$ of oil in the smallest mode. B: $\mathrm{d}(0.5)$. C: Average size of the biggest mode.

the size of oil droplets.

Whey protein stabilized emulsion: $1.67 \mathrm{~kg}$ of whey proteins were added in $7.34 \mathrm{~kg}$ of water in a Process-Pilot 2000/04 (IKA, Germany). Proteins were left to rehydrate under stirring (3170 rpm) for $1 \mathrm{~h}$. Rapeseed oil $(1.0 \mathrm{~kg})$ was added, and stirring was increased $(5610 \mathrm{rpm})$ to make a first emulsion. The emulsion was treated in the high-pressure homogenizer at variable pressures in the same way as the 'lecithinstabilized emulsion'.

\subsection{Characterization}

\subsubsection{Analysis of particle size distribution with dynamic light scattering}

The particle size distributions were obtained with dynamic light scattering using a Mastersizer 2000 (Malvern Instruments, UK). The size distributions of the oil globules were measured by diluting a few drops of emulsion in purified water (resulting obscuration between 12 and 15). Optical properties used for the computations were as follows: 1.33 RI for water (continuous phase), 1.47 RI for the oil (dispersed phase). Computing was based on the Mie theory. For all emulsions, a bimodal distribution was observed. To characterize it, three parameters were recovered (Fig. 1): the size below which were $50 \%$ of the sample particles (median diameter, $\mathrm{d}(0.5), \mu \mathrm{m})$, the average size of the biggest mode (2nd peak diameter, $\mu \mathrm{m}$ ), and the percentage of the smallest droplets. This last parameter was computed by integrating the signal below a specific threshold, empirically set at $0.316 \mu \mathrm{m}$. This was chosen after systematically witnessing a shoulder below this value, an example of which can be seen in Fig. 1 .

Regarding indicators for average droplet size, several were recovered during the experiments: $\mathrm{d}(0.5), \mathrm{D}[4,3]$ and $\mathrm{D}[3,2]$. All three of them were found to be systematically correlated. Thus, only one of them, the $d(0.5)$, was arbitrarily chosen as parameter of interest.

\subsubsection{Statistical analysis}

Statistical analyses were performed using XLSTAT 2015.1 software (Addinsoft, Paris, France). Analysis of variance (ANOVA) was performed to evaluate differences between average values using Tuckey's test. A significance level of $\mathrm{p}<0.05$ was used.

A 2-parameter central-composite design of experiment (DOE) was used to investigate to what extent the emulsion properties depended on Polytron speed and on the duration of sonication (at the lab scale), and on pressure at the different stage (at the pilot scale), by drawing the surface of related responses.

\section{Results and discussion}

\subsection{Selection of the lab scale process parameters}

Two devices were used to make emulsions at the lab scale. A rotorstator homogenizer, the Polytron, was used to produce a first emulsion with a wide droplet distribution of around $10 \mu \mathrm{m}$. Droplets were mainly formed through turbulent and shearing-based mechanisms (Canselier and Poux, 2004a). Next, a sonication treatment was applied to reduce the droplet size. For this step, a combination of shearing and cavitation led to droplet fragmentation (Canselier and Poux, 2004a). Creating emulsions in a high-pressure homogenizer also involves both shearing and cavitation. Thus, by selecting a lab scale approach that combines Polytron and ultrasounds, one can attempt to produce thin stable emulsions while mimicking the processing conditions used at bigger scales.

A first set of experiments was carried out using hydrolyzed lecithin as surfactant in order to select the variables of interest for the Polytron and sonication treatment, and to select appropriate ranges. The concentration of lecithin was constant at $1.0 \mathrm{wt} \%$ to be in excess whatever the size of the droplets. In the Polytron, beyond 2-3 min of treatment, the duration of processing had no noticeable impact on the droplet size distribution of the final emulsion. Conversely, the rotation speed was found to be a key parameter: below $5000 \mathrm{rpm}$, the resulting emulsions were too unstable to be characterized, as the droplets were so large that they creamed very quickly after the end of the treatment. Above $10000 \mathrm{rpm}$, problems of foaming and liquid splashing started to occur. At speeds ranging from 5000 to $10000 \mathrm{rpm}$, emulsions with decent stability (mean diameter around $10 \mu \mathrm{m}$ ) were obtained and they could be transferred to the sonication step before noticeable creaming occurred. For the sonication step, the ultrasound device worked at a constant power level. Thus, the treatment duration was used to monitor the amount of energy transmitted to the sample. To obtain thin droplets, i.e. with a mean diameter around $2 \mu \mathrm{m}$ and $90 \%$ of the droplets with a diameter below $6 \mu \mathrm{m}$, sonication treatment had to last for at least $2 \mathrm{~min}$. Moreover, in these conditions, the results were reproducible (standard deviation $<5 \%$ in the majority of cases). A progressive decrease in droplet size was observed in treatments ranging from 2 to $10 \mathrm{~min}$, for which a mean diameter around $0.8 \mu \mathrm{m}$ was obtained and $90 \%$ of the droplets were smaller than $3 \mu \mathrm{m}$. No more significant modifications occurred after $10 \mathrm{~min}$ (data not shown). Consequently, the ranges used for the 2-parameter central-composite design of experiment (DOE) were set at [5000-10000 rpm] for the Polytron speed, and $[2-10 \mathrm{~min}]$ for the sonication treatment.

\subsection{Selection of the lecithin concentration}

A second set of experiments was conducted in these ranges to identify the optimal concentration for lecithin. Concentrations ranging from 0.3 to $2.0 \mathrm{wt} \%$ were tested. Based on the previous results, three levels of treatment were applied: light processing conditions (5000 rpm Polytron speed for $5 \mathrm{~min}$ followed by $2 \mathrm{~min}$ of sonication), medium processing conditions ( $7500 \mathrm{rpm}-5 \mathrm{~min}$ for Polytron followed by $6 \mathrm{~min}$ of sonication), and strong processing conditions (10000 rpm-5 min for Polytron followed by $10 \mathrm{~min}$ of sonication). Results are reported in Fig. 2.

All emulsions were produced and were sufficiently stable, allowing characterization using the laser granulometer with rather good reproducibility. However, the emulsions obtained using the light process conditions ( $5000 \mathrm{rpm}-5 \mathrm{~min}$ Polytron followed by $2 \mathrm{~min}$ of sonication) were very different from the emulsions obtained using medium and strong process conditions. Likewise, the changes undergone by the three parameters of structure studied were also more erratic in the emulsions produced using the light process conditions and larger 

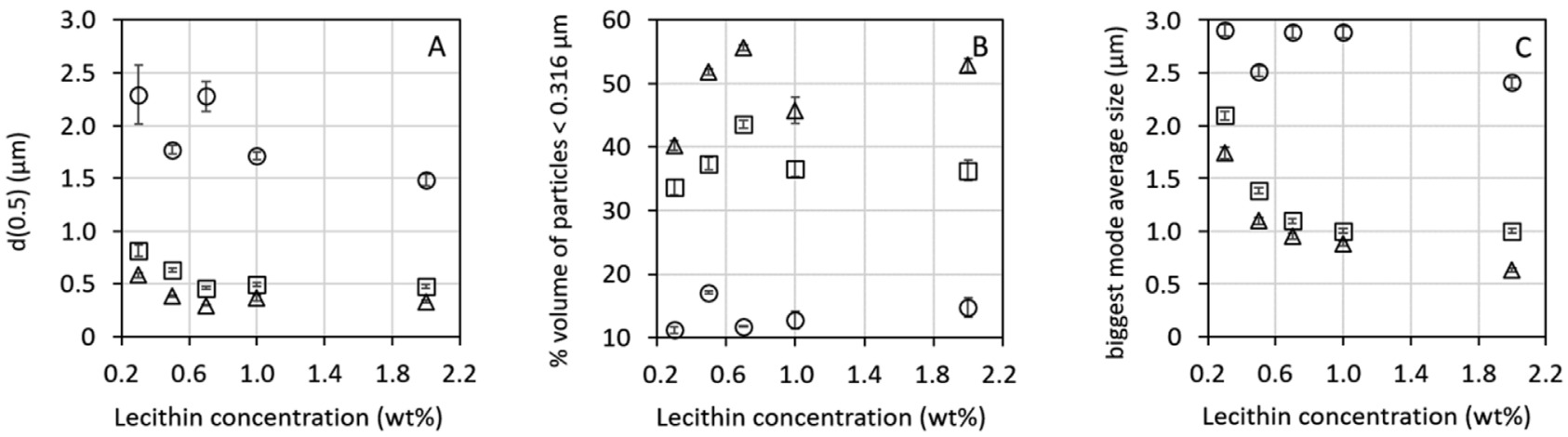

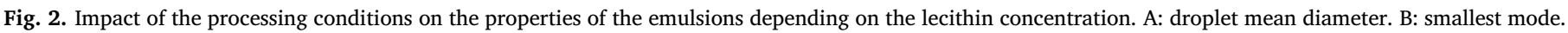

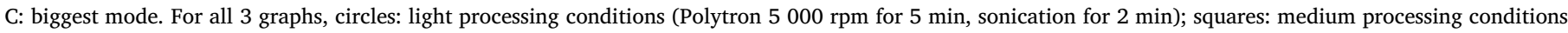
(Polytron $7500 \mathrm{rpm}$ for $5 \mathrm{~min}$, sonication for $6 \mathrm{~min}$ ); triangles: high processing conditions (Polytron $10000 \mathrm{rpm}$ for $5 \mathrm{~min}$, sonication for $10 \mathrm{~min}$ ).

standard deviations were observed for the $\mathrm{d}(0.5)$ with lecithin concentration lower than $1 \mathrm{wt} \%$. Finally, with these process conditions, whatever the lecithin concentration, the $\mathrm{d}(0.5)$ and the biggest mode average size were significantly larger and the percentage of particles with diameters under $0.316 \mu \mathrm{m}$ was small $(10-20 \%$ of the total droplet volume). Thus, even if these light process conditions can be used for lecithin concentration in the range $0.25-2.00 \mathrm{wt} \%$, these results confirmed that $5000 \mathrm{rpm}-5 \mathrm{~min}$ of Polytron, followed by $2 \mathrm{~min}$ of sonication, are the limits below which the lab-scale homogenization will not be efficient enough.

Considering the medium and high process conditions, both the $\mathrm{d}$ (0.5) and biggest mode average size decreased for lecithin concentrations going from 0.3 to $0.7 \mathrm{wt} \%$. On the opposite, the $\%$ volume of particles under $0.316 \mu \mathrm{m}$ increased in that concentration range. Above $0.7 \mathrm{wt} \%$, the diameters no longer changed, showing that with $10 \mathrm{wt} \%$ of oil, $0.7 \mathrm{wt} \%$ of lecithin was enough to cover all the interface even when the minimum diameter is reached, i.e. the maximum interface surface to be covered. Concerning the $\%$ volume of particles under $0.316 \mu \mathrm{m}$, a maximum was observed for $0.7 \mathrm{wt} \%$ of lecithin. For 1 and $2 \mathrm{wt} \%$ of lecithin, values with no noticeable differences in the size distribution curves were obtained, but no interpretation can be proposed. However, $0.7 \mathrm{wt} \%$ appeared to be the optimum lecithin concentration that allowed the production of fine stable emulsions in a reproducible way. The order of magnitude of the measured diameter $(\mathrm{d}(0.5)$ and biggest mode average size) are in good agreement with those measured for example by O'Sullivan et al. (2014) after high presure homogenization of an emulsion containing $10 \mathrm{wt} \%$ of oil and between 0.1 and $1 \mathrm{wt} \%$ of Tween 80 . Thus, $0.7 \mathrm{wt} \%$ of lecithin was selected for the design of experiments performed at both lab and pilot-plant scales.

\subsection{Comparison of lecithin-stabilized emulsions obtained at lab and pilot- plant scales}

Two set of experiments were performed using lecithin, by following a 2-process parameter central-composite design of experiment. As mentioned above, the lab-scale experiment was performed in the ranges: $5000-10000$ rpm for 5 min using the Polytron and 2-10 min of sonication that enabled the production of stable emulsions with the widest possible values for the three parameters of structure. The pilotplant experiment was carried out with the same logic of exploring the widest possible range of variations in emulsion structure characteristics. For that purpose, the full pressure ranges were tested in the first and second stages, i.e. 50-450 bars and 0-140 bars, respectively. At both lab and pilot-plant scales, the response surface obtained for the three parameters of interest $(\mathrm{d}(0.5), \%$ volume of particles under $0.316 \mu \mathrm{m}$, and biggest mode average size) are reported in Fig. 3.

Globally, the three parameters of interest compared pairwise (labscale compared to pilot-plant scale) evolved in the same range of values, the response surface were the same shape and had the same orientation in the 3D graphs. The sizes obtained after the high pressure treatment at pilot scale were as expected, in accordance with those in the literature (Floury et al., 2000). The results also showed that rotorstator turbulence and shearing followed by sonication cavitation and resulting turbulence reduced the size of oil droplets in the same range as pilot homogenization, with the same final size distribution. This means first, that for lecithin-stabilized emulsions, the same microstructure can be obtained with the two emulsifying processes, depending on the intensity of process conditions (Fig. 4A). Second, equivalent process conditions can be given here. The finest emulsions, obtained with high level of pressure in both the first and second stage of the pilot plant, can be also produced at lab scale with $5 \mathrm{~min}$ in the Polytron at $10000 \mathrm{rpm}$ followed by $10 \mathrm{~min}$ of sonication. In both cases, $\mathrm{d}(0.5)$ around $0.8 \mu \mathrm{m}$ is obtained, with biggest mode average sizes around $1 \mu \mathrm{m}$ and about $28 \%$ of particles with diameters $<0.316 \mu \mathrm{m}$. In contrast, the grossest emulsions were obtained with the lightest process condition at both scales: the lowest values of pressure in the 1st and 2nd stages in the case of the pilot plant homogenizer and $5 \mathrm{~min}$ in the Polytron at $5000 \mathrm{rpm}$ followed by $2 \mathrm{~min}$ of sonication at lab scale.

Thus, it is possible to satisfactorily mimic the pilot-plant scale process using a rotor-stator shearing system followed by an ultrasound system, which is very convenient when testing different formulation. In our case, up to eight different formulations were tested in 1 day at labscale, which amounts to a total of $1 \mathrm{~L}$ of emulsion. In comparison, four days would be necessary to test that number of recipes at pilot scale, and would produce about 10 times as much emulsion, requiring 10 times more raw material. Lecithin was used as a model for small surfactants, and one can confidently use the lab-scale process to test different formula. However, for other molecules, especially thermo-sensitive ones, it could be another story. For this reason, similar process conditions at both scales were tested while replacing lecithin by whey proteins.

\subsection{Comparison of whey protein stabilized emulsions obtained at lab and pilot-plant scales}

The response surface obtained at lab and pilot-plant scales using whey proteins are shown in Fig. 5. Although the same orders of magnitude were again obtained for the three parameters of interest when compared pairwise for the lab scale and for the pilot scale, Figs. 5 and 3, several differences can be observed.

Firstly, with whey proteins, droplet size variations versus process conditions were about two times larger than with lecithin. At the same time, the percentage of particles with diameters under $0.316 \mu \mathrm{m}$ was lower, under $20 \%$ for every process condition at both lab and pilot scales. Whey protein showed lower stabilizing properties than lecithin. However, the effect was the same at lab- and pilot-scales, thereby 


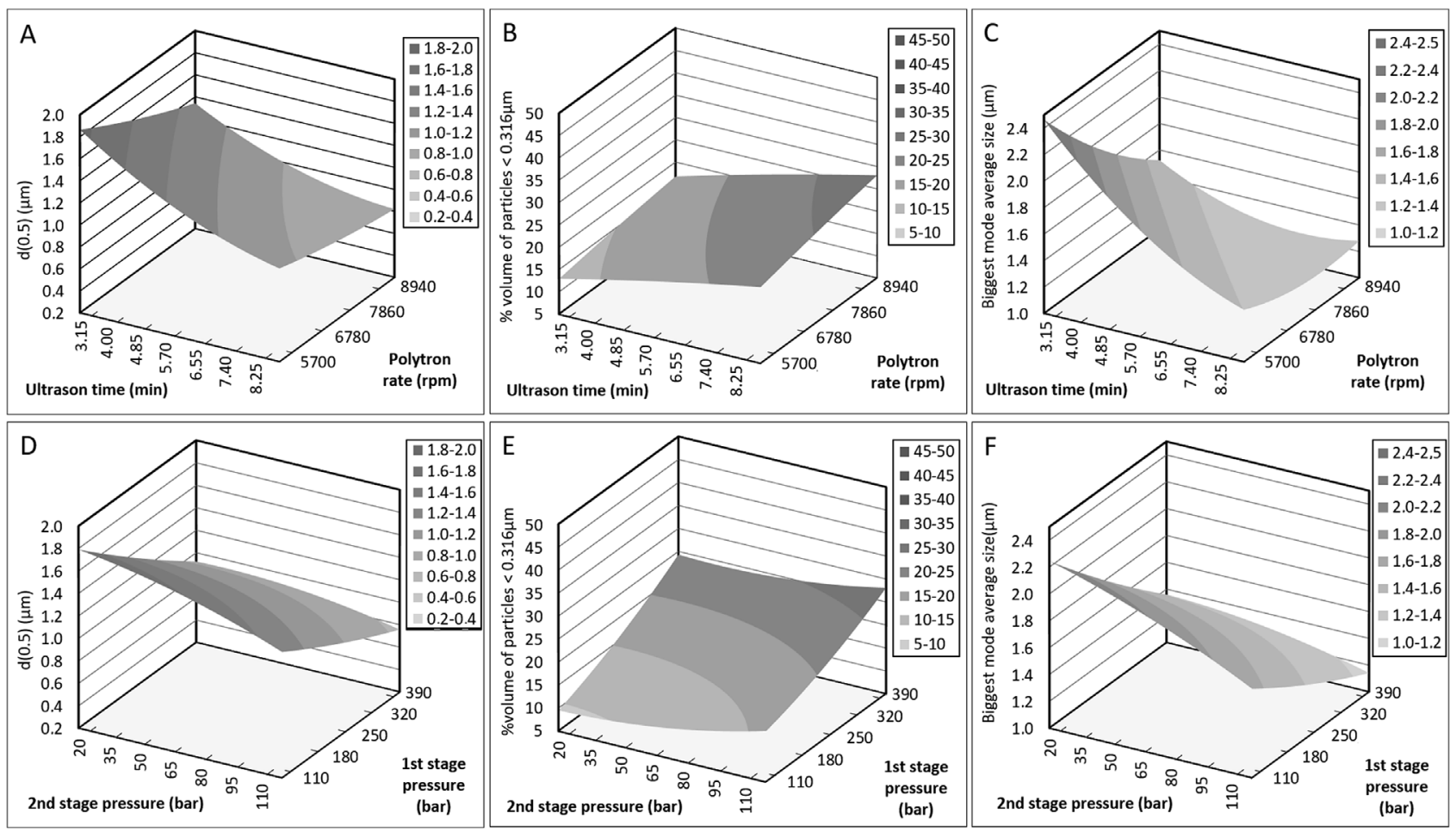

Fig. 3. Impact of the processing conditions on the properties of the lecithin-stabilized emulsion. A, B and C: lab-scale processing and D, E and F: pilot-scale processing. A and D: droplet mean diameter; B and E: smallest mode; C and F: biggest mode.

confirming that the rotor-stator plus sonication process generally produces the same level of energy to break droplets into smaller sizes as the pilot plant.

Secondly, the response surface does not show the same orientation in the 3D graphs nor the same shape for the percentage of particles with diameters under $0.316 \mu \mathrm{m}$. It appears that, as for lecithin, the most efficient process conditions using the pilot-plant are the strongest ones (high pressure in both the first and second stages). At lab scale, although a long sonication time was even more efficient, a lighter initial treatment in the Polytron ( $5000 \mathrm{rpm}$ instead of $10000 \mathrm{rpm}$ ) appeared to be more efficient at producing small droplets $(\mathrm{d}(0.5)$ of $0.7 \mu \mathrm{m}$ instead of $1.3 \mu \mathrm{m}$ and biggest mode average sizes of $1.0 \mu \mathrm{m}$ instead of $1.5 \mu \mathrm{m}$, respectively). Shen et al. (2017) reported slight aggregation of proteins induced by sonication while O'Sullivan et al. (2014) observed no effect on the emulsion stabilizing ability of whey proteins that were pretreated by sonication. Moussier et al. (2019) also showed that a rotorstator plus sonication treatment of a native whey protein solution led to some denaturation, most likely due to local heating during the Polytron step. In addition, these authors observed almost no protein aggregation during a high-pressure treatment at 163 bars, which is in our pressure range. They also described differences in kinetics to reach the interface, depending on whether or not proteins were denatured: native ones adsorbed more rapidly with a stabilizing effect, which may be of interest during homogenization to limit recoalescence. In our experiments, a stronger Polytron treatment probably induced a larger amount of protein aggregates, which adsorbed more slowly at the interface. Consequently, the higher the Polytron speed, the more recoalescence during processing, and hence the larger droplet diameters at the end of
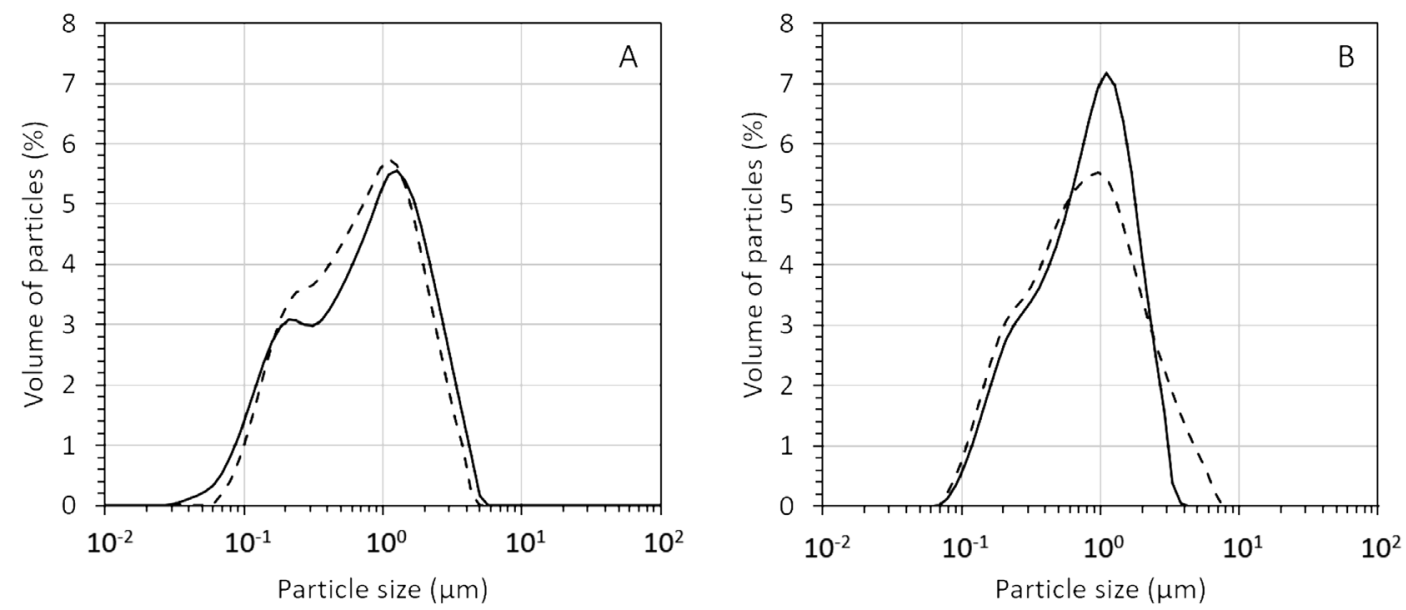

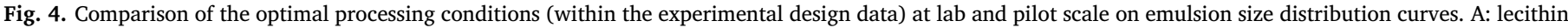

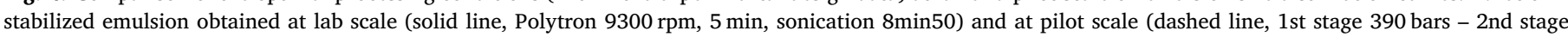

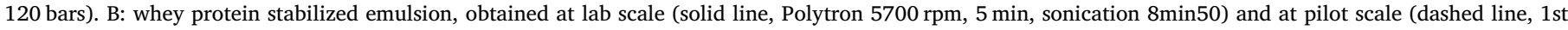
stage 450 bar - 2nd stage 70 bar). 


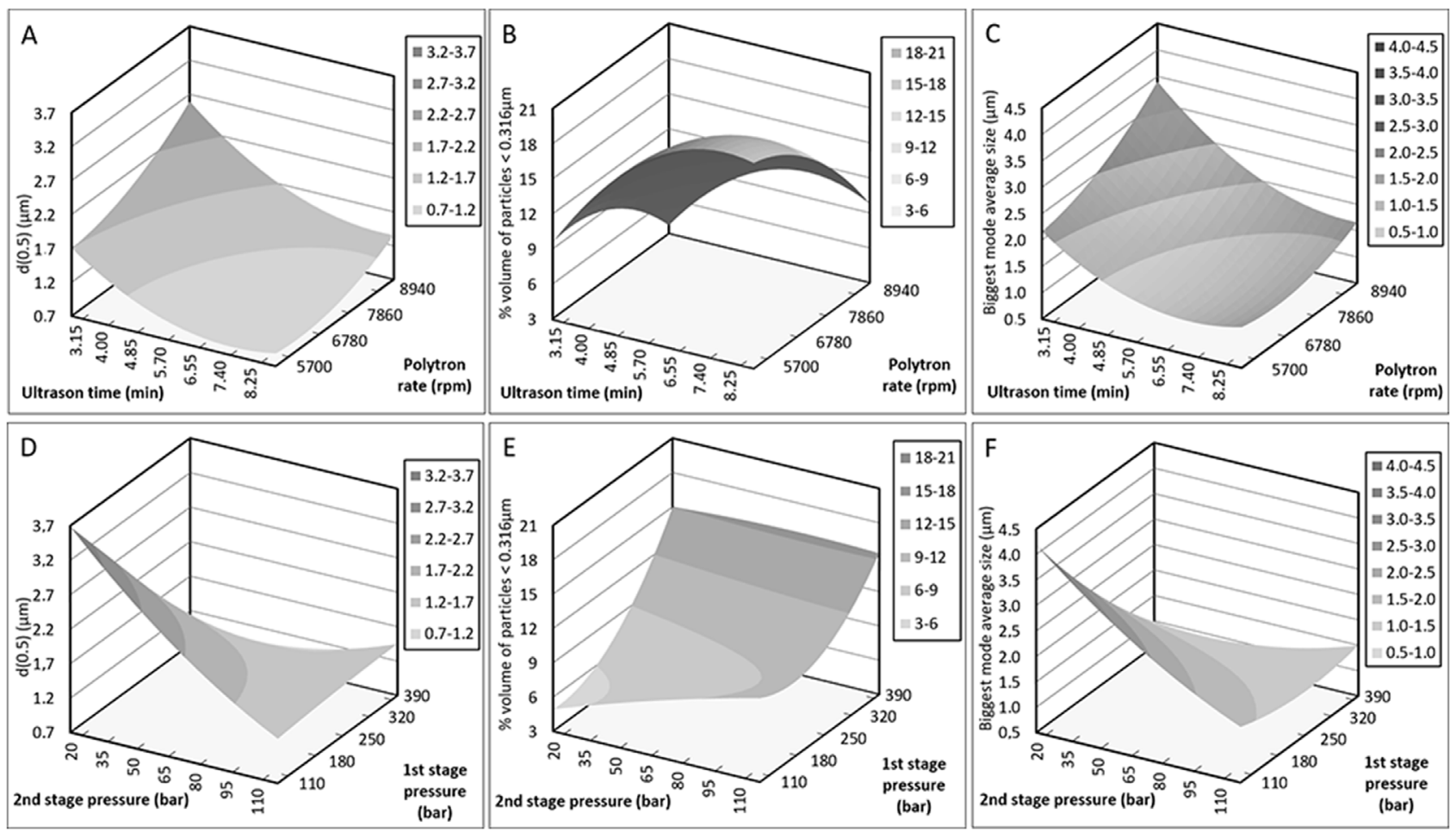

Fig. 5. Impact of the processing conditions on the whey protein-stabilized emulsion properties. A, B and C: lab-scale processing and D, E and F: pilot-scale processing. A and D: droplet mean diameter; B and E: smallest mode; C and F: biggest mode.

rotor-stator step. During the following sonication step, the droplet diameter continued to decrease. However, starting from a higher value and with less efficient partially denatured proteins, the final droplet size was nevertheless larger.

Thus, with thermo-sensitive proteins, it is also possible to satisfactorily mimic the pilot-plant scale process using a rotor-stator shearing system followed by an ultrasound system (Fig. 4B). However, the lab-scale process conditions need to be adapted in order to account for the protein denaturation. The finest emulsions, in that case, can be produced using Polytron $5 \mathrm{~min}$ at $5000 \mathrm{rpm}$ followed by $10 \mathrm{~min}$ of sonication.

\subsection{Some advice concerning control of lab-scale process conditions}

Throughout the lab-scale experiments, we noticed that two process parameters, not discussed so far, had to be carefully controlled in order to guarantee the reproducibility of the trials. The first one concerns the position of the probe during the sonication step. For optimal treatment of the sample, the probe is supposed to be slightly submerged (about $1 \mathrm{~mm}$ ) in the emulsion: the sonication step is based on cavitation-induced droplet fragmentation, which happens in a cone below the probe (Walstra, 1993). The deeper the probe, the smaller the cone, and the larger the volume of untreated material above it. The parameters of interest $(\mathrm{d}(0.5)$, \% volume of particles under $0.316 \mu \mathrm{m}$, and biggest mode average size) obtained for different probe positions are shown in Fig. 6. The positions were as follows: in the middle of the sample (M), at the top (high, or H), and a location between the two (intermediary, or I, i.e. quantitatively at $3 / 4$ of the total sample height).

As expected, the finest emulsions, with a $d(0.5)$ around $0.43 \mu \mathrm{m}$, were obtained when the probe was in the highest position. Deeper immersion ( $\mathrm{M}$ and $\mathrm{I}$ ) led to a significantly bigger mean droplet diameter $(0.55 \mu \mathrm{m})$, and decreased the volume of small particles (39\%, versus around $45 \%$ when the probe was in the highest position). There was no real impact on the size of the biggest mode. It is interesting to compare the results obtained when the probe was in the highest position $(\mathrm{H})$ with those conducted in the same processing conditions when the probe was also positioned at the top of the sample, but its position was not carefully controlled (high uncontrolled position, or $\mathrm{H}$ (nc)). As a result, both the $d(0.5)$ and the volume of small particles turned out to be slightly different to the $\mathrm{H}$ position $(0.47$ versus $0.43 \mu \mathrm{m}$, and $43 \%$ versus $45 \%$ respectively) and the standard error was slightly higher. Thus, the reproducibility of the emulsion properties can quickly deteriorate if not enough attention is paid to the position of the probe. In addition, it should be noted that the emulsification efficiency of the sonication step may have decreased when the probe started to wear out: as its surface became irregular, the input of energy in the cavitation cone probably decreased, hence reducing the droplet fragmentation rate. Thus, it is important to pay careful attention to the condition of the probe when an ultrasonic device is used repeatedly.

The second parameter that needs to be controlled is the temperature of the sample throughout the emulsification process. The droplet size distributions for two lecithin-stabilized emulsions obtained using the same formulation under medium processing conditions (Polytron $7500 \mathrm{rpm}$ for $5 \mathrm{~min}$, sonication for $6 \mathrm{~min}$ ), are shown in Fig. 7. The solid line corresponds to the emulsion obtained under the usual conditions: controlled temperature (kept at around $15^{\circ} \mathrm{C}$ ) with a cooling bath. The dashed line corresponds to an emulsion made at room temperature, with no temperature control (temperature varying between $20^{\circ} \mathrm{C}$ and $35^{\circ} \mathrm{C}$, with the maximum at the end of the Polytron step). In the absence of temperature control, the particle size distribution shifted towards smaller sizes. This was probably due to a modification of the different physical-chemical properties: as the temperature increases, the viscosity of both the aqueous and the oil phases decreases, increasing the emulsification efficiency of the rotor-stator shearing step. Thus, even when surfactants that are not sensitive to temperature are used, temperature control is required to avoid a shift in droplet size. This is even more important for thermo-sensitive emulsifiers, when it is crucial to be able to reproduce the level of denaturation from one trial to the next. 

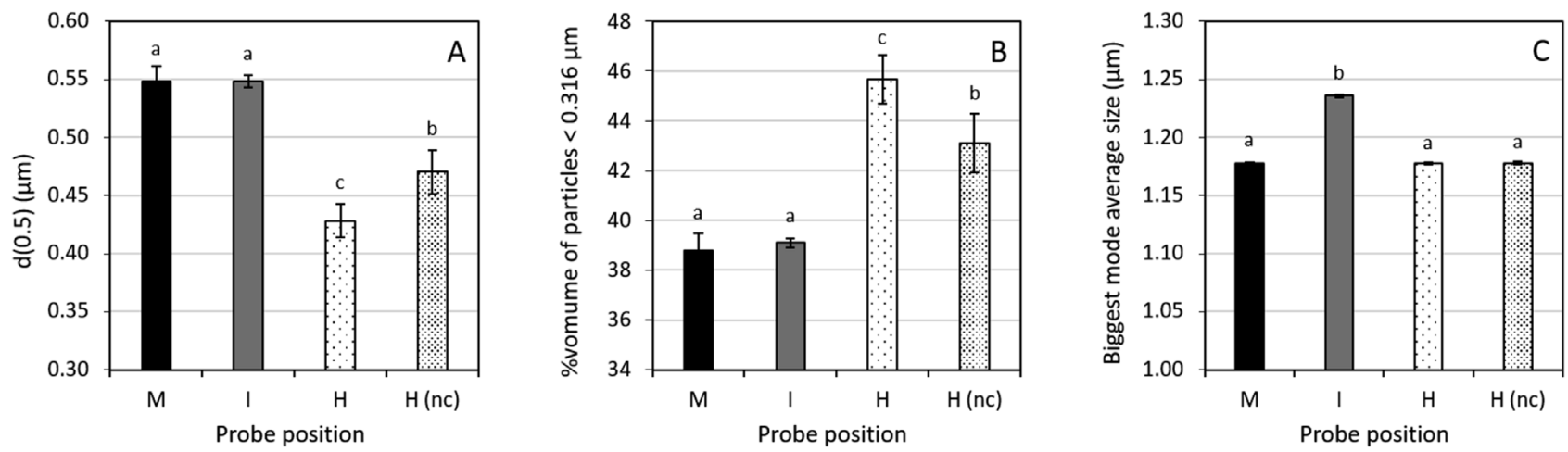

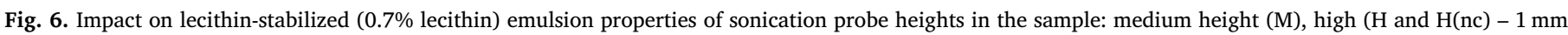

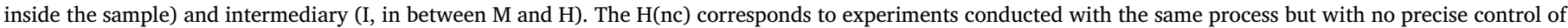
the position of the probe). All experiments were conducted in medium processing conditions (Polytron $7500 \mathrm{rpm}$ for 5 min, sonication for 6 min).

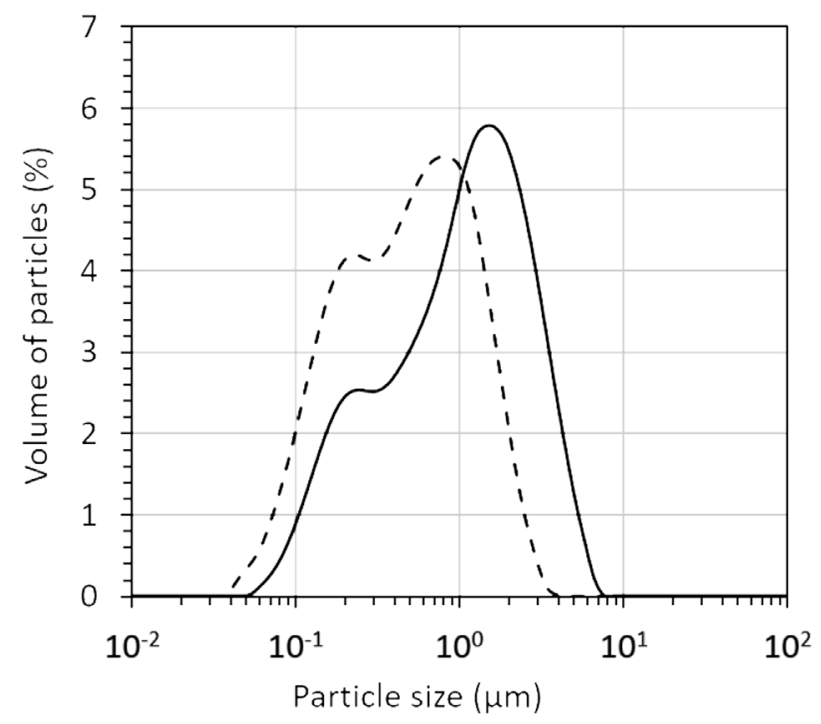

Fig. 7. Impact of temperature on lecithin-stabilized $(0.7 \%$ lecithin) emulsion properties. Both experiments were conducted under medium processing conditions (Polytron $7500 \mathrm{rpm}$ for $5 \mathrm{~min}$, sonication for $6 \mathrm{~min}$ ). Solid line: usual conditions (cooling bath, emulsion temperature kept around $15{ }^{\circ} \mathrm{C}$ ). Dashed line: no temperature control (the entire process took place at room temperature, the emulsion temperature varied between $20^{\circ} \mathrm{C}$ and $35^{\circ} \mathrm{C}$ ).

\section{Conclusions}

The lab-scale process we designed made it possible to reliably mimic what occurred at pilot-scale since the microstructural properties of the lab-scale emulsion were consistent with the pilot-scale properties. A correspondence between process conditions was found for both small surfactant and thermo-sensitive proteins. For lecithin, the strongest conditions in the range studied led to the finest emulsions both at laband pilot-scale. For whey proteins, denaturation issues need to be taken into account. The rotor-stator step is suspected to be responsible for some aggregation due to local heating, which reduces the efficiency of the proteins in stabilizing the interface during the emulsification process. Thus, in presence of thermo-sensitive protein, a lighter Polytron treatment is recommended.

In all cases, the lab process, which consists in a rotor-stator step followed by sonication makes it possible to test four times as many formulations per working day with around ten times less raw materials than required for the pilot homogenizer. Moreover, the cost of the rotor-stator plus sonication equipment is about 10 times less than a pilot-plant homogenizer. Provided that the temperature of the sample, the position depth and the state wear of the sonication probe are controlled, many formulations can be very efficiently tested prior to upscaling.

\section{Acknowledgements}

The authors thank Ines Chakib (AgroParisTech, France) for her contribution to the preliminary experiments. This work received support from the French National Research Agency under the 'Investissemnt d'Avenir" program (reference ${ }^{\circ}$ ANR-11-IDEX-0003-02).

\section{References}

Burgaud, I., Dickinson, E., Nelson, P.V., 1990. An improved high-pressure homogenizer for making fine emulsions on a small scale. Int. J. Food Sci. Technol. 25, 39-46.

Canselier, J.P., Poux, M., 2004a. Emulsion preparation: theoretical notions and practical aspects. Pharmaceut. Chem. J. 16-21.

Canselier, J.P., Poux, M., 2004b. Techniques et appareillage, procédés d'émulsification. Technique de l'ingénieur, vol. 152. Editions TI Sciences et Techniques, Paris, pp. 1-12 J2.

Courthaudon, J.L., Dickinson, E., 1991. Competitive adsorption of lecithin and $\alpha$-casein in oil-in-water emulsions. J. Agric. Food Chem. 39, 1365-1368.

Dickinson, E., 1992. An Introduction to Food Colloids. Oxford Science publication, Oxford, pp. 207.

Dickinson, E., 2015. Structuring of colloidal particles at interfaces and the relationship to food emulsion and foam stability. J. Colloid Interface Sci. 449, 38-45.

Dickinson, E., Iveson, G., 1993. Adsorbed films of $\beta$-lactoglobulin + lecithin in thehydrocarbon-water and triglyceride-water interfaces. Food Hydrocolloids 6, 533-541.

Fang, Y., Dalgleish, D.G., 1996. Competitive adsorption between dioleoyphosphatidylcholine and sodium caseinate on oil-water interfaces. J. Agric. Food Chem. 44, 59-64.

Floury, J., Desrumaux, A., Lardieres, J., 2000. Effect of high-pressure homogenization on droplet size distributions and rheological properties of model. J. Dairy Sci. 1, 127-134. https://doi.org/10.3168/jds.2008-1797.

Gonzalez-Jordan, A., Nicolai, T., Benyahia, L., 2018. Enhancement of the particle stabilization of water-in-water emulsions by modulating the phase preference of the particles. J. Colloid Interface Sci. 530, 505-510. https://doi.org/10.1016/j.jcis.2018. 04.088.

Mat, D.J.L., Le Feunteun, S., Michon, C., Souchon, I., 2016. In vitro digestion of foods using pH-stat and the INFOGEST protocol: impact of matrix structure on digestion kinetics of macronutrients, proteins and lipids. Food Res. Int. 88, 226-233.

Mat, D.J.L., Cattenoz, T., Souchon, I., Michon, C., Le Feunteun, S., 2018. Monitoring the kinetics of pepsin hydrolysis using pH-stat titration: from static to semi-dynamic gastric in vitro digestions. Food Chem. 239, 268-275.

McClements, D.J., 2015. Food Emulsions: Principles, Practice and Techniques, third ed. CRC Press, Boca Raton, Florida, pp. 609.

Mezdour, S., Lepine, A., Erazo-Majewicz, P., Ducept, F., Michon, C., 2008. Oil/water surface rheological properties of hydroxypropylcellulose (HPC) alone and mixed with lecithin: contribution to emulsion stability. Colloid. Surf. Physicochem. Eng. Asp. 331, 76-83.

Moussier, M., Bosc, V., Michon, C., Pistre, V., Chaudemanche, C., Huc-Mathis, D., 2019. Multi-scale understanding of the effects of the solvent and process on whey protein emulsifying properties: application to dairy emulsion. Food Hydrocolloids 8, 869-879. https://doi.org/10.1016/j.foodhyd.2018.08.052.

Nilson, L., Bergenstal, B., 2006. Adsorption of hydrophobic modified starch at oil-water interfaces during emulsification. Langmuir 22, 8770-8776.

Oberli, M., Douard, V., Beaumont, M., Jaoui, D., Devime, F., Laurent, S., Chaumontet, C., Mat, D., Le Feunteun, S., Michon, C., Davila, A.M., Fromentin, G., Tomé, D., Souchon, I., Leclerc, M., Gaudichon, C., Blachier, F., 2018. Lipo-protein emulsion structure in the diet affects protein digestion kinetics, intestinal mucosa parameters and 
microbiota composition. Mol. Nutr. Food Res. 62 (2), 1700570. https://doi.org/10 1002/mnfr.201700570. IF 5.151.

O'Sullivan, J., Arellano, M., Pichot, R., Norton, I., 2014. The effect of ultrasound treatment on the structural, physical and emulsifying properties of dairy proteins. Food Hydrocolloids 42, 386-396. https://doi.org/10.1016/j.foodhyd.2014.05.011.

Shen, X., Fang, T., Gao, F., Guo, M., 2017. Effects of ultrasound treatment on physicochemical and emulsifying properties of whey proteins pre- and post-thermal aggregation. Food Hydrocolloids 63, 668-676. https://doi.org/10.1016/j.foodhyd. 2016.10.003.

Walstra, P., 1983. Formation of emulsions. In: In: Becher, P. (Ed.), Encyclopedia of Emulsion Technology, vol. 1. Marcel Dekker, New York, pp. 57-127.

Walstra, P., 1993. Principles of emulsion formation. Chem. Eng. Sci. 48 (2), 333-349. 